ON LIVING WITH

T E L E V IS I O N 
CONSOLE-ING PASSIONS

TELEVISION AND CULTURAL POWER

Edited by Lynn Spigel 


\section{ON LIVING WITH}

T ELEVISION

A MY HOLDSWORTH

Duke University Press Durham and London 2021 
() 2021 Duke University Press

All rights reserved

Printed in the United States of America on acid-free paper $\infty$ Designed by Courtney Leigh Richardson

Typeset in Warnock Pro by Copperline Book Services

Library of Congress Cataloging-in-Publication Data

Names: Holdsworth, Amy, [date] author.

Title: On living with television / Amy Holdsworth.

Other titles: Console-ing passions.

Description: Durham : Duke University Press, 2021. | Series:

Console-ing passions | Includes bibliographical references

and index.

Identifiers: LCCN 2021010943 (print)

LCCN 2021010944 (ebook)

ISBN 9781478013839 (hardcover)

ISBN 9781478014751 (paperback)

ISBN 9781478022060 (ebook)

Subjects: LCSH: Television-Social aspects. | Television-

Psychological aspects. | Feminist television criticism. | Queer theory. | Disability studies. | BISAC: PERFORMING ARTS /

Television / History \& Criticism

Classification: LCC PN1992.6.H585 2021 (print) |

LCC PN1992.6 (ebook) | DDC 302.23/45-dc23

LC record available at https://lccn.loc.gov/2021010943

LC ebook record available at https://lccn.loc.gov/2021010944

Cover art: Watching T v before bed. Amy and Jessica Holdsworth, ca. 1984. 
For my family 
This page intentionally left blank 